\title{
A Portfolio Theory Approach to Software Vendor Selection
}

\author{
Marius RĂDULESCU ${ }^{1}$, Constanța Zoie RĂDULESCU ${ }^{2}$ \\ ${ }^{1}$ Institute of Mathematical Statistics and Applied Mathematics, Casa Academiei Române, \\ 13, Calea 13 Septembrie, Bucharest 5, RO-050711, ROMANIA \\ mradulescu.csmro@yahoo.com \\ ${ }^{2}$ National Institute for Research and Development in Informatics, \\ 8-10 Averescu Avenue, Bucharest 1, RO-011455, ROMANIA \\ radulescucz@yahoo.com
}

\begin{abstract}
The paper presents a minimum risk model, inspired from the financial portfolio theory, for the selection of a software vendor. The performance of the software products offered by potential software vendors is evaluated by several experts regarding several criteria. The minimum risk model has several constraints. One of the constraints is a complementarity constraint. Other constraints are connected with the available budget and the expected performance of the software products. A procedure for solving the minimum risk model is presented and a numerical example is analyzed.
\end{abstract}

Keywords: Software vendor selection, portfolio theory, minimum risk model, complementarity constraints, decision support.

\section{Introduction}

The task of selecting project portfolios is an important and recurring activity in many organizations.

Project selection is a process of strategic significance aimed at evaluating individual projects or groups of projects and then choosing to implement a set of them so that the objectives of the organization may be achieved. The project selection is a complex task. Many factors must be taken into account especially in the case of uncertainty or interrelationships among projects. There are many techniques available to assist in this process. The supplier selection problem is a special case of the project portfolio selection problem.

The software vendor selection problem is a special case of the supplier selection problem.

In the second section we present a literature review on the approaches to the project selection problem and to the software vendor selection problem.

In the third section we present an original binary mathematical programming model for the software vendor selection problem under risk and limited resources which is inspired from a previous model presented in Rădulescu and Rădulescu [23]. Our model includes several opinions belonging to a group of evaluator experts. These opinions generate the risk. The project risk is greater if experts' opinions have a greater degree of dispersion. Since the projects do not have the same impact under every criterion and the relative importance of the criteria is vague definite, at least at the start of the decision process the solution of the real problem is not an easy task. In the fourth section is presented a numerical example for the minimum risk model that aims to find the best software vendor.

\section{Literature Review}

Many organizations have been making serious efforts to analyze a large set of project proposals in order to choose project portfolios which maximize the performance, meet the resource constraints and minimize the risk. The project proposals may be intended for strategic R\&D planning (selection of directions, topics or projects), the development of new commercial products, the management and the implementation of organizational change, the management, the development and the implementation of information technology etc.

In the process of project portfolio selection, decision makers must cope with significant uncertainties in the investment required, time necessary to complete the project, the 
availability of resources when required, and the likelihood of successful project completion. These may depend on project size, complexity, and project team experience. In addition, there may be multiple criteria to be satisfied, and the choice of projects typically is made by a committee that represents different organizations or companies that may be involved in the project. Selecting a project portfolio is a semi-structured decision.

The prioritization problem, in various forms, has received substantial attention over the past several decades. A great variety of methods for project selection exist in the literature. See for example Heidenberger, Stummer [13] and Carazo et al [3]. The scoring method, DePiante, Jensen [8] and Coldrick et al [5], the multiattribute utility theory, Duarte, Reis [8] and the Analytical Hierarchy Process, Suh et al [28] are among the most widely used. These models aim at ranking the project set, after which resources are distributed following the priorities established in the ranking. However, this approach assumes that candidate projects are independent, which is not always true, and the interrelation-ships among them means that the best individual projects do not necessarily make the best portfolio, Chien [4]. These limitations have led to increasing interest in mathematical programming models as they can integrate such considerations into the project portfolio selection process. This interest is supported by advances in the technical procedures used to solve the models generated, Weber et al [30].

In Ghasemzadeh, et al. [11] a zero-one integer linear programming model was proposed for selecting and scheduling an optimal project portfolio, based on the organization's objectives and constraints such as resource limitations and interdependence among projects. The proposed model not only suggests projects that should be incorporated in the optimal portfolio, but it also determines the starting period for each project. Scheduling consideration can have a major impact on the combination of projects that can be incorporated in the portfolio, and may allow the addition of certain projects to the portfolio that could not have been selected otherwise.

Another model of the same type was discussed in Ghasemzadeh and Archer [12]. The model was integrated in a decision support system.
Two original zero-one mathematical programming models for project selection problem under risk and limited resources were investigated in Rădulescu and Rădulescu, [22] and [23]. The models include several resources and expert evaluator opinions which generate the risk. The project risk is greater if experts' opinions have a greater degree of dispersion. Several versions of the models are discussed. In Rădulescu and Rădulescu [23] a decision support system (DSS), called PROSEL (PROject analysis and SELection system), intended to assist managers in making high quality project portfolio selections was presented.

Every organization needs suppliers and no organization can exist without suppliers. Therefore, the organizations approach to the procedures for the selection of the appropriate supplier is of vital importance. To select the best supplier, it is essential for the organization's manager to make an analytical decision based upon tangible and intangible criteria. The choice and management of a supplier has to be congruent with the organization strategy. The supplier selection problem, in various forms, has received substantial attention over the past several decades.

A fuzzy AHP approach for supplier selection problem has been made in Ayhan [1]. A case study in a GEARMOTOR company was investigated. A new hybrid model for the supplier selection decision was studied in Dominic [7]. An approach of the selection of vendor IT outsourcing based on portfolio management was studied in Fridgen and Müller [9].

An exploratory study using a systematic literature review on the barriers in the selection of offshore software development outsourcing vendors was made in Khan et al [18].

An investigation of factors influencing clients in the selection of offshore software outsourcing vendors was performed in Khan et al [17]. In Wang [29] a quality function deployment for conducting the vendor assessment and the supplier recommendation for business-intelligence systems was used. An interesting review of methods for supporting the supplier selection may be found in de Boer et al [2]. 
A special case of the supplier selection problem is the software vendor selection problem. The software vendor selection is a complex decision problem. Of course in making this decision the manager (that is the decision maker) can involve several expert evaluators. Consequently the vendor selection decision becomes a group decision. The manager and the expert evaluators try to find the best software product (the best software vendor) for the purchasing. They assign importance values to the software evaluation criteria and to the software vendor reputation. The manager assigns importance values to the reputation of the expert evaluators. The divergent opinions among the expert evaluators represent a risk in manager's perception. The manager is risk averse. He will try to manage the software vendor selection risk. The manager will assign importance values to risks for each evaluation criteria. There exists a vast literature on the software vendor and the software product selection. A multi criteria group decision making approach for collaborative software selection problem can be found in Kara and Cheikhrouhou [15]. An integrated decision making approach for the ERP system selection is described in Karsak and Ozogul [16]. An approach to the software vendor selection based on the Fuzzy Analytic Hierarchy Process can be found in Yuen and Lau [31]. A comprehensive survey on the evaluation and selection the software packages can be found in Jadhav and Sonar [14].

A more precise formulation of a software vendor selection model inspired from the financial portfolio theory will be presented in the section 3 . We recall that the portfolio theory was developed since the beginning of the second half of the $20^{\text {th }}$ century. The main concepts of portfolio theory were introduced in Markowitz's seminal paper [19]. See also Markowitz's book [20]. Portfolio theory was considered an important advance in the mathematical modeling of finance. It is a mathematical formulation of the concept of diversification in investing, with the aim of selecting a collection of investment assets that has lower overall risk than any other combination of assets with the same expected return.

There exist many applications of portfolio theory to domains that do not imply finance such as agriculture, sire selection, forestry, biodiversity, energy, sustainable production planning, project selection etc. For supplementary references regarding the portfolio theory and its applications to nonfinancial areas see the following references: Rădulescu and Rădulescu [24]-[27], Fulga [10] and Popescu, Fulga [21].

\section{A Minimum Risk Model for the Software Vendor Selection}

Suppose that a manager wants to purchase a software product from $m$ firms that commercialize software products ( $m$ software vendors). The software product offered by every software vendor will be evaluated by $q$ experts regarding $p$ criteria. The experts will give for each criterion and each software vendor a score ranging from 1 to 10 .

Let $I_{1}=\{1,2, \ldots, m\}$ be the set of software vendors, $I_{2}=\{1,2, \ldots, p\}$ the set of evaluation criteria, $I_{3}=\{1,2, \ldots, q\}$ the set of expert evaluators.

Let $\xi_{j r}$ be the score of the software product offered by the software vendor $j$ regarding the criterion $r$. Note that $\xi_{j r}$ is a random variable.

Denote by $M$ the manager's budget available for purchasing the software product.

Denote by $c_{j}$ the cost of the software product commercialized by the software vendor $j$.

Denote by $W$ the lower limit for the overall expected score of the software product when it is evaluated regarding criterion $r$. The manager wants to purchase the software product from a software vendor whose overall expected score is greater or equal than $W$. Let $c j$ be the cost of the software product at the software vendor $j$.

Denote by $w_{1 r}$ the weight that shows the importance of criterion $r$ in the vendor selection process.

Denote by $w_{2 j}$ the weight that shows the manager's risk aversion for the software vendor $j$. The greater is the value of $w_{2 j}$, the smaller is the reputation of vendor $j$.

Denote by $w_{3 j}$ the weight which shows the manager's risk aversion according to the criterion $r$ for purchasing the software product. The greater is the positive number $w_{3 r}$, the 
greater is the manager's aversion for the risk connected to criterion $r$. The decision variable is the binary $m$ dimensional vector $x=\left(x_{j}\right)$.

$x_{j}=1$ if the software product is purchased from the software vendor $j$.

$x_{j}=0$ if the software product is not purchased from the software vendor $j$.

The vector $x=\left(x_{j}\right)$ will be called a portfolio.

The risk of selecting the software product from software vendor $j$ regarding the criterion $r$ is defined as the variance of the random variable $\xi_{j r}$, which is denoted with $\operatorname{Var}\left(\xi_{j r}\right)$.

The risk of selecting the software product from the software vendor $j$ is defined as follows:

$$
V_{j}=\sum_{r=1}^{p} w_{3 r} \operatorname{Var}\left(\xi_{j r}\right)
$$

The overall risk for purchasing the portfolio $x=\left(x_{j}\right)$ is:

$$
\begin{aligned}
R(x) & =\sum_{j=1}^{m} w_{2 j} V_{j} x_{j} \\
& =\sum_{j=1}^{m} \sum_{r=1}^{p} w_{2 j} w_{3 j r} \operatorname{Var}\left(\xi_{j r}\right) x_{j}
\end{aligned}
$$

The constraints of the minimum risk model are the following:

- $\quad \sum_{r=1}^{q} w_{1 r} E\left(\xi_{j r}\right) x_{j} \geq W x_{j}$ for every $j \in I_{1}$, (the performance constraint)

- $\quad \sum_{j=1}^{m} c_{j} x_{j} \leq M$ (the budget constraint)

- $\quad \sum_{j=1}^{m} x_{j}=1$ (the complementarity constraint)

This constraint ensures that the software product will be purchased from only one software vendor.

The decision maker looks for a software vendor such that it minimize the portfolio risk, satisfies the constraints and has a performance greater than a given level $\mathrm{W}$.

The mathematical model for the risk minimization problem is the following:

$$
\mid \begin{aligned}
& \min \left[\sum_{j=1}^{m} \sum_{r=1}^{p} w_{2 j} w_{3} j r \operatorname{Var}\left(\xi_{j r}\right) x_{j}\right] \\
& \sum_{r=1}^{q} w_{1 r} E\left(\xi_{j r}\right) x_{j} \geq W x_{j} \text { for every } j \in I_{1} \\
& \sum_{j=1}^{m} c_{j} x_{j} \leq M \\
& \sum_{j=1}^{m} x_{j}=1 \\
& x_{j} \in\{0,1\} \text { for every } j \in I_{1}
\end{aligned}
$$

An important problem is the determination of the range of parameters for the user parameters $M$ and $W$. If we denote $M_{1}=\min _{1 \leq j \leq m} c_{j}$ and $M_{2}=\max _{1 \leq j \leq m} c_{j}$ then the range of parameter $M$ is the interval $\left[M_{1}, M_{2}\right]$.

Denote $A(M)=\left\{j \in I_{1}: c_{j} \leq M\right\}$,

$$
\begin{aligned}
& W_{1}=\min \left\{\sum_{r=1}^{q} w_{1 r} E\left(\xi_{j r}\right): j \in A(M)\right\} \text { and } \\
& W_{2}=\max \left\{\sum_{r=1}^{q} w_{1 r} E\left(\xi_{j r}\right): j \in A(M)\right\} .
\end{aligned}
$$

Then the range of parameter $W$ is the interval $\left[W_{1}, W_{2}\right]$.

In order to solve the minimum risk model we need the evaluation of experts for each criterion and each vendor and also a vector of weights that shows the reputation of each expert.

Let $u_{\text {jrs }}$ be the score given by the expert $s$ to the software product offered by vendor $\mathrm{j}$ on criterion $r$.

Let $w_{4 s}$ the weight that shows the reputation of expert $s$. Then for every $j \in I_{1}$ and $r \in I_{2}$ we have

$$
\begin{aligned}
& E\left(\xi_{j r}\right)=\frac{1}{q} \sum_{s=1}^{q} w_{4 s} u_{j r s}, \\
& \operatorname{Var}\left(\xi_{j r}\right)=\frac{1}{q} \sum_{s=1}^{q} w_{4 s}^{2} u_{j r s}^{2}-\left(\frac{1}{q} \sum_{s=1}^{q} w_{4 s} u_{j r s}\right)^{2}
\end{aligned}
$$

The input data in the minimum risk model are: 
1. The $m$-dimensional vector $c=\left(c_{1}, c_{2}, \ldots, c_{m}\right)$ which describe the prices asked by the software vendors.

2. The $m \times p \times q$ matrix $U=\left(u_{j r s}\right)$ which describes the scores given by the expert evaluators.

3. The user parameters are $M, W$ and the vectors of weights:

$$
\begin{aligned}
& w_{1}=\left(w_{11}, w_{12}, \ldots, w_{1 p}\right), \\
& w_{2}=\left(w_{21}, w_{22}, \ldots, w_{2 m}\right), \\
& w_{3}=\left(w_{31}, w_{32}, \ldots, w_{3 p}\right) \text { and } \\
& w_{4}=\left(w_{41}, w_{42}, \ldots, w_{4 q}\right) .
\end{aligned}
$$

\subsection{A procedure for determining the set of software vendors recommended to be selected}

$$
\begin{aligned}
& \text { Step } 1 . \quad \text { Compute } M_{1}=\min _{1 \leq j \leq m} c_{j} \text { and } \\
& M_{2}=\max _{1 \leq j \leq m} c_{j} .
\end{aligned}
$$

Step 2. Select a value for the parameter $M$ in the interval $\left[M_{1}, M_{2}\right]$.

Step 3. Determine the set: $A(M)=\left\{j \in I 1: c_{j} \leq M\right\}$.

Step 4. Compute:

$$
\begin{aligned}
& W_{1}=\min \left\{\sum_{r=1}^{q} w_{1 r} E\left(\xi_{j r}\right): j \in A(M)\right\} \text { and } \\
& W_{2}=\max \left\{\sum_{r=1}^{q} w_{1 r} E\left(\xi_{j r}\right): j \in A(M)\right\} .
\end{aligned}
$$

Step 5. Select a value for the parameter $W$ in the interval $\left[W_{1}, W_{2}\right]$.

Step 6. Determine the set

$$
B(W)=\left\{j \in A(M): \sum_{r=1}^{q} w_{1 r} E\left(\xi_{j r}\right) \geq W\right\} .
$$

Step 7. Compute:

$$
a=\min \left\{\sum_{r=1}^{p} w_{2 j} w_{3 j r} \operatorname{Var}\left(\xi_{j r}\right): j \in B(W)\right\}
$$

Step 8. Determine the set

$$
C=\left\{j \in B(W): \sum_{r=1}^{p} w_{2 j} w_{3 j r} \operatorname{Var}\left(\xi_{j r}\right)=a\right\} \text { of }
$$

the optimal software vendors.

\section{Numerical Example}

Suppose that the manager wants to buy a software product of type ERP (Enterprise Resource Planning) with a specified set of characteristics. The software product is offered by $m=7$ software vendors.

It is evaluated according to $p=18$ criteria. Many criteria are taken from the standard, ISO/IEC 9126-1.

The evaluation criteria are connected with 7 main criteria: functionality, reliability, usability, efficiency, maintainability, portability, price and vendor reputation.

The software vendor proposals are evaluated by $q=10$ expert evaluators.

In Table 1 are presented the software vendor prices (in euro) and the weights for the experts' reputation.

Table 1. The software vendor prices and reputation

\begin{tabular}{|c|c|c|}
\hline $\begin{array}{c}\text { Nr. } \\
\text { Crt. }\end{array}$ & $\begin{array}{c}\text { The price of } \\
\text { software vendor } \\
\text { (vector } \mathbf{c} \text { ) }\end{array}$ & $\begin{array}{c}\text { The weights that } \\
\text { shows the Vendor's } \\
\text { reputation } \mathbf{w}_{2}\end{array}$ \\
\hline 1 & 3700 & 1.0 \\
\hline 2 & 3900 & 1.3 \\
\hline 3 & 4200 & 1.6 \\
\hline 4 & 4500 & 1.8 \\
\hline 5 & 4600 & 2.0 \\
\hline 6 & 4750 & 2.3 \\
\hline 7 & 4800 & 2.5 \\
\hline
\end{tabular}

In Table 2 are listed the criteria and the subcriteria considered in our numerical example for the software vendor selection. The criteria from the minimum risk model are the subcriteria from Table 2. 
Table 2. The criteria for the software vendor selection

\begin{tabular}{|c|c|c|c|c|}
\hline $\begin{array}{l}\text { Nr. } \\
\text { Crt. }\end{array}$ & Criterion & Sub-criterion & $\begin{array}{c}\text { Manager's risk aversion for the } \\
\text { criterion } \\
\text { Weights are given by the } \\
\text { vector } w_{3}\end{array}$ & $\begin{array}{c}\text { Importance for the } \\
\text { performance of the criterion } \\
\text { Weights are given by the } \\
\text { vector } w_{1}\end{array}$ \\
\hline & Functionality & & & \\
\hline 1 & & Suitability & 0.95 & 0.32 \\
\hline 2 & & Accuracy & 0.95 & 0.32 \\
\hline 3 & & Interoperability & 0.47 & 0.23 \\
\hline \multirow[t]{2}{*}{4} & & Security & 0.95 & 0.30 \\
\hline & Reliability & & & \\
\hline 5 & & Fault Tolerance & 0.95 & 0.31 \\
\hline 6 & & Recoverability & 0.47 & 0.25 \\
\hline 7 & & Understandability & 0.61 & 0.30 \\
\hline 8 & & Learnability & 0.61 & 0.30 \\
\hline 9 & & Operability & 0.47 & 0.23 \\
\hline \multirow[t]{2}{*}{10} & & Attractiveness & 0.61 & 0.21 \\
\hline & Efficiency & & & \\
\hline 11 & & Time Behaviour & 0.74 & 0.25 \\
\hline \multirow[t]{2}{*}{12} & & Resource Utilization & 0.74 & 0.25 \\
\hline & Maintainability & & & \\
\hline 13 & & Stability & 0.47 & 0.20 \\
\hline \multirow[t]{2}{*}{14} & & Testability & 0.18 & 0.14 \\
\hline & Portability & & & \\
\hline 15 & & Adaptability & 0.18 & 0.10 \\
\hline \multirow[t]{2}{*}{16} & & Installability & 0.58 & 0.15 \\
\hline & Other criteria & & & \\
\hline 17 & & Price & 0.95 & 0.35 \\
\hline 18 & & Vendor reputation & 0.95 & 0.35 \\
\hline
\end{tabular}

In Table 3 are presented the selected software vendor for various values of the user parameters $M$ and $W$.

\section{Conclusion}

In this paper we presented a model for the selection of a software vendor. The model is inspired from the financial portfolio theory. In order to evaluate the software products from the vendor proposals several criteria were chosen. The model is a binary programming model that takes into account opinions of several expert evaluators for each criterion. Consequently the vendor selection decision is a group decision.

One of the model constraints is a complementarity constraint. A simple procedure for solving the model is presented and a numerical example is analyzed.

Table 3. The selected software vendor for various values of the user parameters $M$ and $W$.

\begin{tabular}{|c|c|c|c|}
\hline Nr. Crt. & $M$ & $W$ & The selected vendor \\
\hline 1 & 3700 & 7.1 & 3 \\
\hline 2 & 3800 & 6.4 & 3 \\
\hline 3 & 4000 & 6.8 & 4 \\
\hline 4 & 4300 & 7.5 & 6 \\
\hline 5 & 4600 & 5.3 & 7 \\
\hline 6 & 4750 & 6.5 & 7 \\
\hline 7 & 4800 & 7.4 & 3 \\
\hline
\end{tabular}


The research connected with the present model can be extended and a more complex model can be built that takes into account the selection of several software products.

\section{Acknowledgements}

This work was supported by a grant of the Romanian National Authority for Scientific Research, CNCS - UEFISCDI, project number PN-II-ID-PCE-2011-3-0908.

\section{REFERENCES}

1. AYHAN, M. B., A Fuzzy AHP Approach for Supplier Selection Problem: A Case Study in a GEARMOTOR Company, International Journal of Managing Value and Supply Chains (IJMVSC) vol. 4(3), 2013, pp. 11-23.

2. De BOER, L., E. LABRO, P. MORLACCHI, A Review of Methods Supporting Supplier Selection, European Journal of Purchasing \& Supply Management, vol. 7, 2001, pp. 75-89.

3. CABAllero, R., A. F. CARAZO, T. GÓMEZ, F. M. GUERRERO, A. G. HERNÁNDEZ-DÍAZ, J. MOLINA, Solving a Comprehensive Model for Multiobjective Project Portfolio Selection, Computers \& Operations Research, vol. 37, 2010, pp. 630-639.

4. CHIEN, C., A Portfolio-Evaluation Framework for Selecting R\&D Projects. R\&D Man., vol. 32(4), 2002, pp. 359-368.

5. COLDRICK, S., J. HANNIS, P. IVEY, P. LONGHURST, An R\&D Options Selection Model for Investment Decisions, Technovation, vol. 25(3), 2005, pp. 185-193.

6. DEPIANTE, A., A. JENSEN, A Practical R\&D Project-Selection Scoring Tool, IEEE Trans. on Engineering Management, vol. 46(2), 1999, pp. 158-170.

7. DOMINIC P. D. D., O. I. FOONG, G. KANNABIRAN, A. A. WHAB, A New Hybrid Model for the Supplier Selection
Decision, Intl. J. of Business Information Systems, vol. 5(3), 2010, pp. 230-247.

8. DUARTE B. P. M., A. REIS, Developing a Project Evaluation System based on Multiple Attribute Value Theory, Computers and Operations Research, vol. 33(5), 2006, pp. 1488-1504.

9. FRIDGEN, G., H. V. MUELlER, An Approach for Portfolio Selection in Multi-vendor IT Outsourcing, 7, 2011, ICIS 2011 Proceedings. Paper 8. http://aisel.aisnet.org/icis2011/proceedings/ projmanagement $/ 8$

10. FUlGA C., Convexification Technique and Portfolio Optimization, Studies in Informatics and Control, vol. 22(4), 2013, pp. 285-290.

11. GHASEMZADEH, F., N. P. ARCHER, P. IYOGUN, A Zero-one Model for Project Portfolio Selection and Scheduling, Journal of Operational Research Society, vol. 50(7), 1999, pp. 745-755.

12. ARCHER, N. P., F. GHASEMZADEH, Project Portfolio Selection through Decision Support. Decision Suport Systems, vol. 29, 2000, pp. 73-88.

13. HEIDENBERGER, K., C. STUMMER, Research and Development Project Selection and Resource Allocation: A Review of Quantitative Modelling Approaches, Intl. Journal of Management Reviews, vol. 1, 1999, pp. 197-224.

14. JADHAV, A. S., R. M. SONAR, Evaluating and Selecting Software Packages: A Review, Info. and Software Technology, vol. 51, 2009, pp. 555-563.

15. CHEIKHROUHOU, N., S. S. KARA, A Multi-criteria Group Decision Making Approach for Collaborative Software Selection Problem, Journal of Intelligent \& Fuzzy Systems: Applications in Engineering and Technology, vol. 26(1), 2014, pp. 37-47.

16. KARSAK, E. E., C. O. OZOGUL, An Integrated Decision Making Approach for ERP System Selection, Expert 
Systems with Applications, vol. 36, 2009, pp. 660-667.

17. AHMAD, R., S. U. KHAN, M. NIAZI, Factors Influencing Clients in the Selection of Offshore Software Outsourcing Vendors: An Exploratory Study using a Systematic Literature Review, Journal of Systems and Software, vol. 84(4), 2011, pp. 686-699.

18. AHMAD, R., S. U. KHAN, M. NIAZI, Barriers in the Selection of Offshore Software Development Outsourcing Vendors: An Exploratory Study using a Systematic Literature Review, Information and Software Technology, vol. 53(7), 2011, pp. 693-706.

19. MARKOWITZ, H. M., Portfolio selection, The Journal of Finance, vol. 7, issue 1, 1952, pp. 77-91.

20. MARKOWITZ, H. M., Portfolio Selection: Efficient Diversification of Investments, New York: John Wiley \& Sons, 2nd ed. Basil Blackwell, 1991.

21. POPESCU, C. C., C. FULGA, Possibilistic Optimization with Application to Portfolio Selection, Proceedings of the Romanian Academy, Series A Mathematics, Physics, Technical Sciences, Information Science, vol. 12, issue 2, 2011, pp. 88-94.

22. RĂDULESCU, C. Z., M. RĂDULESCU, Decision Analysis for the Project Selection Problem under Risk, 9-th IFAC/IFORS/ IMACS /IFIP Symposium On Large Scale Systems: Theory And Applications, Bucharest, 2001, pp. 243-248.

23. RĂDULESCU, M., C. Z. RĂDULESCU, Project Portfolio Selection Models and Decision Support, Studies in Informatics and Control, vol. 10(4), 2001, pp. 275-286.
24. RĂDULESCU, M., S. RĂDULESCU, C. Z. RĂDULESCU, Mathematical Models for Optimal Asset Allocation (ROU), Editura Academiei Române, Bucureşti, 2006.

25. RĂDULESCU, C. Z., M. RĂDULESCU, A Decision Support Tool based on a Portfolio Selection Model for Crop Planning under Risk, Studies in Informatics and Control, vol. 21(4), 2012, pp. 377-382.

26. RĂDULESCU, M., C. Z. RĂDULESCU, Mean-Variance Models with Missing Data, Studies in Informatics and Control, vol. 22 (4), 2013, pp. 299-306.

27. RĂDULESCU, M., C. Z. RĂDULESCU, Gh. ZBĂGANU, A Portfolio Theory Approach to Crop Planning under Environmental Constraints, Ann. of Op. Res., vol. 219, 2014, pp. 243-264.

28. BAEK, K., C. SUH, E. SUH, Prioritizing Telecommunications Technologies for Long-range R\&D Scheduling to the Year 2006, IEEE Trans. on Eng. Man., vol. 41(3), 1994, pp. 264-275.

29. WANG, C. H., Using Quality Function Deployment to Conduct Vendor Assessment and Supplier Recommendation for Business-Intelligence Systems, Computers \& Industrial Engineering, vol. 84, 2015, pp. 24-31.

30. WEBER, R., B. WERNERS, H. J. ZIMMERMANN, Scheduling Models for Research and Development, European Journal of Operational Research, 48, 1990, pp.175-188.

31. YUEN, K. K. F., H. C. W. LAU, Software Vendor Selection using Fuzzy Analytic Hierarchy Process with ISO/IEC 9126, IAENG International Journal of Computer Science, vol. 35(3), 2008, pp. 267-274. Retrieved from http://www.iaeng.org/IJCS/ issues_v35/issue_3/IJCS_35_3_03.pdf. 